\title{
Treatment of chronic low back pain - new approaches on the horizon
}

\author{
Nebojsa Nick Knezevic ${ }^{1-3}$ \\ Shane Mandalia' \\ Jennifer Raasch' \\ Ivana Knezevic' \\ Kenneth D Candido ${ }^{1-3}$ \\ 'Department of Anesthesiology, \\ Advocate Illinois Masonic \\ Medical Center, ${ }^{2}$ Department of \\ Anesthesiology, ${ }^{3}$ Department of \\ Surgery, University of Illinois, \\ Chicago, IL, USA
}

This article was published in the following Dove Press journal: Journal of Pain Research

10 May 2017

Number of times this article has been viewed
Correspondence: Nebojsa Nick Knezevic Department of Anesthesiology, Advocate Illinois Masonic Medical Center, 836 W. Wellington Ave., Suite 48I5, Chicago, IL 60657, USA Tel +l 7732965619

Fax +I 7732965362

Email nick.knezevic@gmail.com

\begin{abstract}
Back pain is the second leading cause of disability among American adults and is currently treated either with conservative therapy or interventional pain procedures. However, the question that remains is whether we, as physicians, have adequate therapeutic options to offer to the patients who suffer from chronic low back pain but fail both conservative therapy and interventional pain procedures before they consider surgical options such as discectomy, disc arthroplasty, or spinal fusion. The purpose of this article is to review the potential novel therapies that are on the horizon for the treatment of chronic low back pain. We discuss medications that are currently in use through different phases of clinical trials (I-III) for the treatment of low back pain. In this review, we discuss revisiting the concept of chemonucleolysis using chymopapain, as the first drug in an intradiscal injection to reduce herniated disc size, and newer intradiscal therapies, including collagenase, chondroitinase, matrix metalloproteinases, and ethanol gel. We also review an intravenous glial cell-derived neurotrophic growth factor called artemin, which may repair sensory nerves compressed by herniated discs. Another new drug in development for low back pain without radiculopathy is a subcutaneous monoclonal antibody acting as nerve growth factor called tanezumab. Finally, we discuss how platelet-rich plasma and stem cells are being studied for the treatment of low back pain. We believe that with these new therapeutic options, we can bridge the current gap between conservative/interventional procedures and surgeries in patients with chronic back pain.
\end{abstract}

Keywords: chronic low back pain, clinical trials, chemonucleolysis, tanezumab, artemin, PRP, stem cells, new therapy

\section{Introduction}

Back pain is a common global problem and according to the Centers for Disease Control and Prevention (CDC), it is the second leading cause of disability among American adults. ${ }^{1}$ The current mainstay of conservative therapy includes the use of nonsteroidal anti-inflammatory drugs (NSAIDs), acetaminophen, muscle relaxants, or even a short course of opioid pain medication in conjunction with non-pharmacological strategies such as physical therapy, all of which lead to improvement in a majority of patients. However, if conservative therapy does not provide symptomatic relief, or if pain persists as moderate-to-severe ( $\geq 4 / 10$ on a numeric pain rating scale), more invasive treatments such as epidural steroid injections, facet injections, and radiofrequency ablations are generally considered. Unfortunately, even these more invasive procedures have not been shown to decrease the need for subsequent surgeries in patients with chronic pain secondary to herniated lumbar intervertebral discs. 
The question is whether we as physicians have other therapeutic options to offer to patients who fail both conservative therapy and interventional pain procedures, before considering surgical options such as discectomy, disc arthroplasty, or spinal fusion. The purpose of this article is to review the potential new therapies that are on the horizon for the treatment of chronic low back pain. We discuss medications that are currently in different phases of clinical trials (I-III) for the treatment of low back pain.

\section{Anatomy and pathophysiology}

The intervertebral disc is crucial to the function of the spine. The discs sit between the contiguous vertebrae and act as a shock absorber, helping enhance fluidity and strength of spinal motion, and dispersion of axial and torsional forces. The intervertebral disc is made of a collagenous exterior annulus fibrosus and a gelatinous interior nucleus pulposus (NP). ${ }^{2}$ The NP is $85 \%$ aqueous and is composed of collagen type II and few chondrocyte-like cells. It has a high proteoglycan and water content and serves to resist axial compression. The annulus fibrosus consists of 15-50 concentric lamellae that are attached to the cartilaginous endplate of each vertebra and is composed of type I collagen and a few fibroblasts, giving it a high tensile force (Figure 1). ${ }^{3-5}$ The nutritional pathway of the disc is precarious; the disc itself is relatively avascular, relying on oxygen and nutrient diffusion from the blood supply to the endplates. This means that oxygen tension and glucose concentration are lowest at the center of the disc (Figure 2).${ }^{6-8}$ A decrease in nutrients and oxygen supply to the disc due to loss of end plate permeability makes it difficult for the disc to maintain its matrix and cell turnover (although minimal), which leads to degeneration and cellular apoptosis. ${ }^{4}$ With maturation, proteoglycans and aggrecan molecules are degraded, resulting in loss of glycosaminoglycans and decreased osmotic pressure. ${ }^{3,4}$ This affects the load-bearing function of the disc, resulting in loss of disc height and bulging of nuclear contents posteriorly through the thinning or torn annulus and the relatively weak posterior longitudinal ligament. The loss of hydration and desiccation can lead to increased stress concentrations on the endplate and the annulus, which have been associated with discogenic pain. ${ }^{9}$ Collagen type II fibers become more denatured due to disrupted enzyme activity. ${ }^{4}$ Aggrecan molecules, which have been shown to inhibit neural ingrowth, also degrade in degenerating discs, leading to

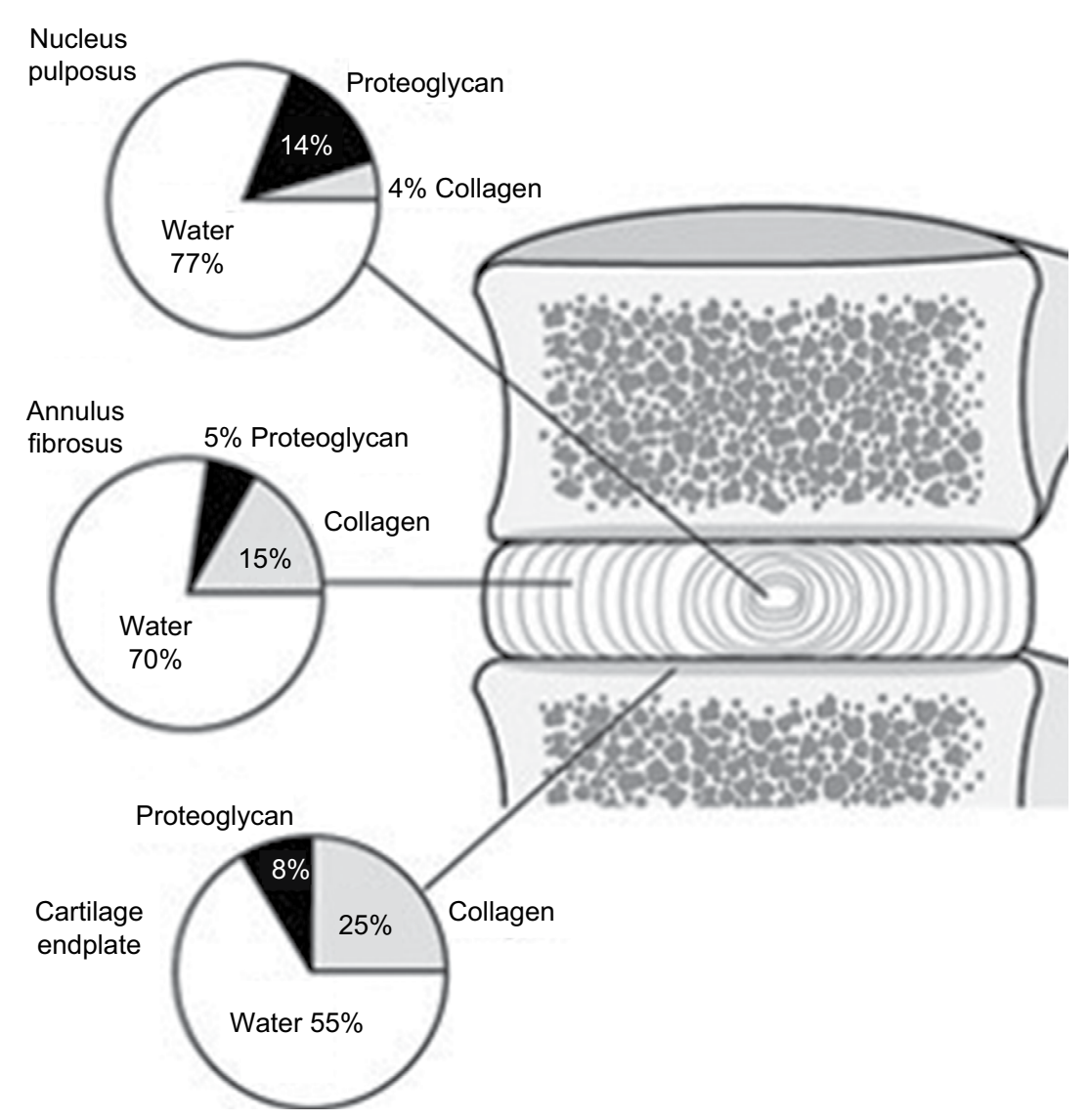

Figure I The relative proportion of the three main components of the adult human intervertebral disc; nucleus pulposus, annulus fibrosus, and the cartilage endplate. Note: Reprinted with permission from Copyright 20II ILO's Encyclopaedia. Roberts S, Urban S, Jill PG. Encyclopedia of Occupational Health and Safety. Intervertebral Discs. Available from: http://www.iloencyclopaedia.org/part-i-47946/musculoskeletal-system/I 7-6-musculoskeletal-system/intervertebral-discs. ${ }^{5}$ 
A

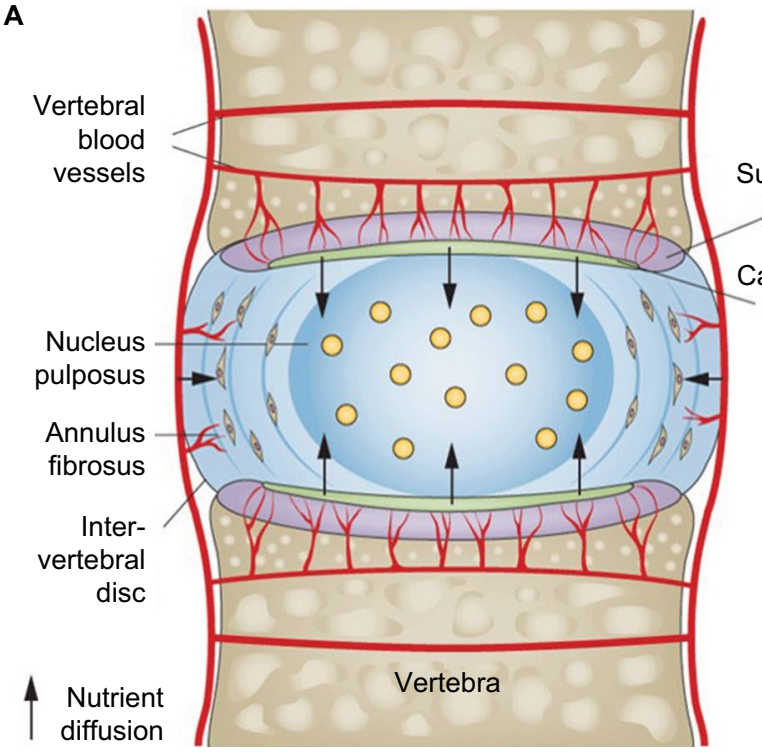

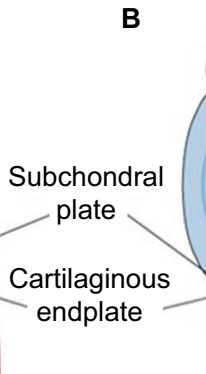

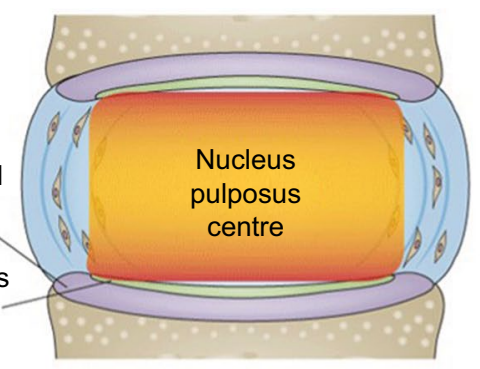

C

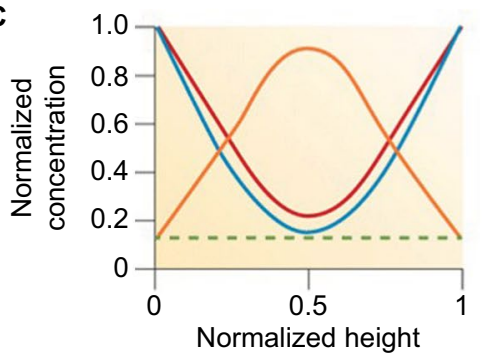

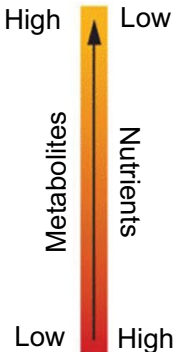

-Oxygen

- Glucose

- Lactic acid

- - Critical level

Figure 2 Pathways of nutrient supply in a normal intervertebral disc.

Notes: (A) The avascular intervertebral disc is supplied by surrounding vertebral blood vessels and nutrients must diffuse from the outside of the disc inward, down their concentration gradients. (B) Demonstrates the relationship of concentration gradients as nutrients are at their lowest concentration in the middle of the disc whereas metabolites and waste products are at their highest concentrations because of relative difficulty to diffuse out of the area. (C) Schematic showing normalized concentration gradients of glucose, oxygen, and lactic acid across the nucleus and endplate. Nutrient concentrations must remain above the critical levels to maintain cell viability and activity. Copyright @2014. Reprinted from Nature Publishing Group. Huang YC, Urban JP, Luk KD. Intervertebral disc regeneration: do nutrients lead the way? Nat Rev Rheumatol. 2014;10(9):561-566. ${ }^{8}$

neural ingrowth that also contributes to chronic pain., ${ }^{3,10,11}$ In addition, loss of disc height in a loaded degenerated disc can lead to abnormal loading of apophyseal joints, potentially leading to osteoarthritic changes. ${ }^{12}$

These physiological changes make intervertebral discs more susceptible to herniation through radial tears, most commonly. Intervertebral disc herniation occurs when there is displacement of the disc material through radial annular tears beyond the limits of the intervertebral disc margin at the annulus. The material extending outside the disc annulus can include portions of NP, cartilaginous endplate, fragmented apophyseal bone, annular tissue or all of these. A majority of the time, herniated material contains mainly NP, either alone or in combination with the aforementioned tissues. Disc herniations are generally associated with disc degenerative changes; however, a healthy intervertebral disc under too much of a torque or load can also herniate. ${ }^{13,14}$ Due to the convex shape of the vertebrae, mid and outer annular fibers are subjected to higher strain when a weight load is applied to the spinal column in some degree of flexion, making the annulus more vulnerable to radial or longitudinal tears, especially in the posterolateral region. ${ }^{14}$ Obese people or those having jobs with prolonged sitting, repetitive heavy lifting, twisting or vibration exposure will be more prone to disc degeneration and herniation. ${ }^{2,3,13,15}$ All these factors along with cigarette smoking and intense physical activity can accelerate disc degeneration beyond what would occur with normal aging and maturation.

\section{Symptoms}

Most physicians see patients with symptomatic intervertebral disc herniation because they are experiencing either leg or low back pain with or without a variable degree of motor or sensory loss. Pain in this case is caused by not only the mechanical effect of the herniated material on the nerve root but also from chemical and autoimmune reactions causing root inflammation. ${ }^{14,16,17}$ The nucleus is laden with inflammatory mediators, including phospholipase A2, histamine, lactate, bradykinin, substance $\mathrm{P}$, calcitonin-gene related peptide, and vasoactive intestinal peptide among others. From a radiological perspective, it has generally been shown that the severity of lower extremity pain is associated with more severe disc disease, but this is not always the case. ${ }^{16}$ Large free fragments can oftentimes be totally asymptomatic. ${ }^{18}$ In cases where only a small amount of herniated material causes pain, chemical factors from inflammatory mediator liberation are likely responsible for the pain. Unfortunately, not even magnetic resonance imaging (MRI) is able to give us enough information to determine whether a patient's operant pathology is mechanical/compressive or chemical/inflammatory. ${ }^{17}$ Provocation discography has been cited as one method that can differentiate chemical from mechanical disc pathology. 
The degenerative process of intervertebral discs tends to escalate with age, while the natural course of intervertebral disc herniation lends itself to a favorable prognosis in the majority of cases. It has been shown that between $45 \%$ and $80 \%$ of patients experience at least $30 \%$ reduction in disc herniation due to disc desiccation, with many experiencing complete reduction of symptoms even with modest dehydration. ${ }^{17,19}$ Acutely severe pain usually abates in $1-2$ weeks in most people. Full recovery is dependent on the presence or absence of a neurologic deficit. Mild deficits usually recover in 6-12 weeks while severe neurologic loss can take up to 1year to recover fully. It has also been demonstrated in one study that between $9 \%$ and $35 \%$ of patients with acute low back pain continued to have symptoms that were clinically significant at 6 months, with no further improvement even when reassessed at 2 years. ${ }^{20}$ The same study demonstrated a recurrence rate of $47 \%$ between 6 months and 2 years after the initial episode of acute low back pain. ${ }^{20}$ While this helps to shed some light on the timeline between acute and chronic pain, as well as pain recurrence caused by intervertebral disc herniation, many studies continue to endorse considering surgery after 6 weeks in case of continued severe pain or lower extremity motor function loss. ${ }^{15,17}$

\section{Treatment}

Given that many people with intervertebral lumbar disc herniation have a high likelihood of recovery spontaneously without surgical interventions, and the fact that some people are not good surgical candidates, there are many other methods that are used to manage pain from this condition. The areas of treatment can be divided into conservative management and invasive treatments. When starting conservative management, most people begin with a combination of pharmacological and non-pharmacological strategies. Pharmacological interventions include acetaminophen, NSAIDs, muscle relaxants, tramadol, corticosteroids, and even short courses of opioids for moderate-to-severe pain, in accordance with the World Health Organization's stepladder approach to managing chronic pain. Pharmacological strategies are mainly aimed at symptom control until pain abates. Non-pharmacological strategies include physical therapy, acupuncture, chiropractic manipulation, or therapies such as yoga, tai chi, or meditation. The majority of people improve with conservative treatments exclusively or in conjunction with a multimodal analgesic regimen as mentioned previously. $2,15,17,21$

If conservative treatment does not provide symptom relief, more invasive treatments are generally considered. Epidural glucocorticoid injections have long been touted as the first step in invasive interventional management of symptomatic intervertebral herniated discs. Whether by a lumbar interlaminar, caudal, or transforaminal approach, epidural injections have been shown to reduce pain scores and disability mainly in the short term (usually at 2 weeks) as well as delay the need for surgical intervention for as long as 13-28 months. ${ }^{22}$ Patients may experience relief for a period of time but may require additional repeat injections following pain recurrence. ${ }^{20}$ Whereas the efficacy of steroids in epidural injections is controversial, a meta-analysis of 10 randomized controlled trials of epidural injections for the treatment of radicular low back pain confirmed that epidural injections of local anesthetic with or without steroids resulted in significant improvement in pain and functionality, as well as decreased opioid consumption. ${ }^{23}$ However, epidural injections have not been shown to decrease the need for eventual subsequent surgery in patients with chronic pain secondary to herniated intervertebral disc. ${ }^{2,15,17}$ Are there any other treatment options for patients who fail both conservative and interventional procedures before undergoing surgical procedures (discectomy, disc arthroplasty, spinal fusion, etc.) in the management of symptomatic lumbar radicular low back pain (Figure 3)?

\section{Chemonucleolysis with chymopapain}

Chemonucleolysis is a process that was first described by Smith in $1964 . .^{24}$ It consists of an injection of proteolytic enzymes into the intervertebral disc for the purpose of dissolving the herniated NP. The main enzyme used for this purpose was chymopapain, which is a non-specific proteoglycanase derived from the papaya plant. It was found to only have effect on cartilaginous tissue material from displaced intervertebral disc, that is the NP and the annulus fibrosus, without affecting surrounding tissues, including collagen or nervous tissues. ${ }^{25}$ Essentially, injecting chymopapain directly into the intervertebral disc caused disc narrowing due to dissolution of the extruded material. Animal studies supported the safety of intradiscal chymopapain enzyme and Smith was able to publish his initial report on 10 patients who underwent chemonucleolysis in $1964 .{ }^{24}$ After much controversy and vocal opposition to the adoption of chemonucleolysis in clinical practice, and following additional research, chymopapain was approved by the Food and Drug Administration (FDA) in 1982, 18 years after the initial report describing its benefits was published. ${ }^{25}$

Careful selection of patients for chemonucleolysis was crucial to the success of the treatment. ${ }^{26,27} \mathrm{Kim}$ et al analyzed the prognostic factors of 3000 patients who improved 


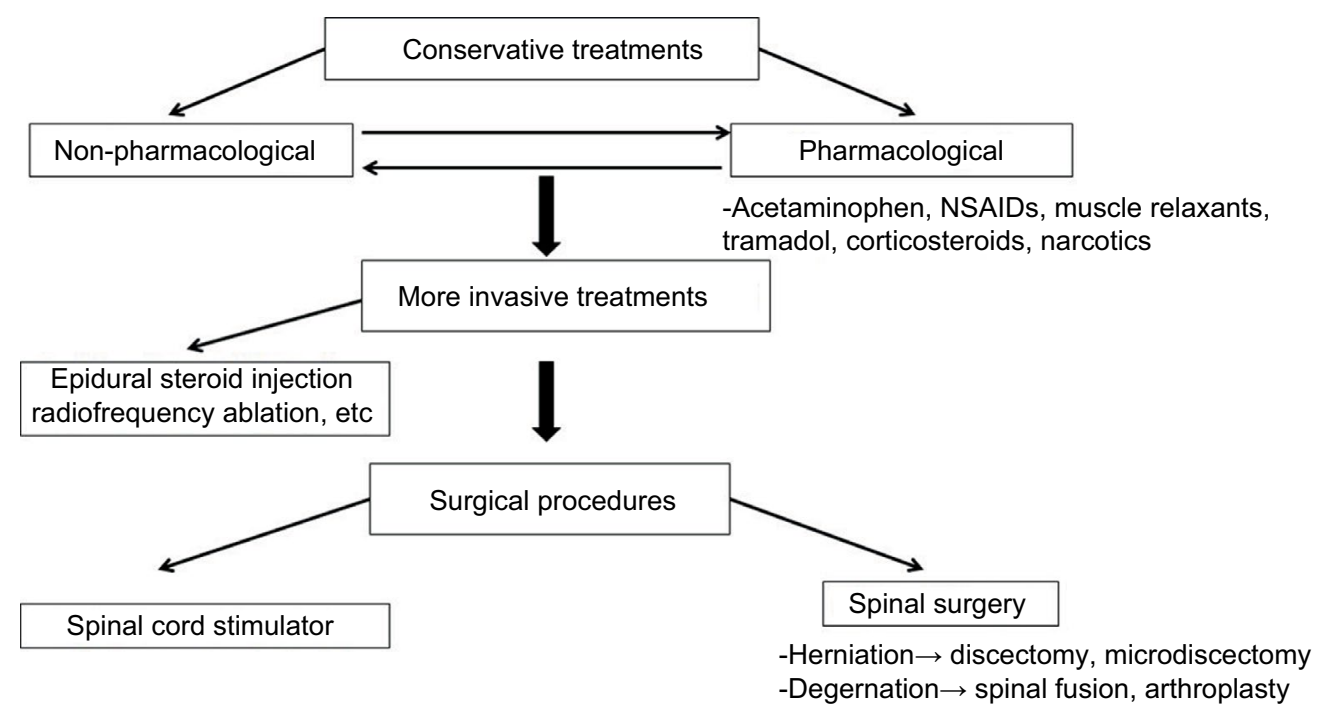

Figure 3. Current common stepwise approach to management of low back pain.

Notes: Initially, non-invasive measures are initiated consisting of oral medications along with non-pharmacologic measures such as physical therapy. This is followed by invasive treatments such as epidural injections or radiofrequency ablation. If these measures fail, surgical options are considered, which include discectomy or spinal fusion. Abbreviation: NSAIDs, nonsteroidal anti-inflammatory drugs.

following chymopapain injection and found a statistically significant difference in patients who complained primarily of leg pain (88\%) versus low back pain (59\%), as well as more improvement in patients with a moderate or severe straight leg raise versus mild or no limitation. ${ }^{26}$ Radiologic assessment of patients prior to treatment played a substantial role in patient selection as well. Soft disc herniations, especially in the posterolateral direction, showed much higher success rates $(94.7 \%)$ versus patients with diffuse bulging herniations $(65.7 \%) .{ }^{26}$ Prognostic factors that were also shown to favor good outcomes included young age, shorter duration of symptoms, and lack of bony spurs or calcifications on radiologic studies. ${ }^{26}$ Because selection of subjects must be precise for chemonucleolysis, sometimes it so happened that patients who qualified as surgical candidates would not meet the criteria for selection for chemonucleolysis. ${ }^{26}$

Logistically, there are multiple steps that need to be followed in order for chemonucleolysis to work seamlessly. Prior to the start of the procedure, patients need to be tested for the chymopapain antibody with a simple skin test in order to screen for those susceptible to anaphylactic reaction. ${ }^{28}$ Initially, general anesthesia was used for the procedure, but eventually local anesthetic with monitored anesthesia care (if necessary) was preferred. Needle insertion was performed under fluoroscopy in order to confirm accurate placement in the center of the intervertebral lumbar disc. ${ }^{28}$ While chemonucleolysis is no longer performed using chymopapain, early studies paved the way for the development of a safe and effective intervention technique.
Nordby et al reported 45 studies between 1985 and 1993 by looking at records of 7335 patients who underwent chemonucleolysis with chymopapain and found a $76 \%$ success rate. ${ }^{29}$ Another prospective study followed patients who had failed conservative therapy who underwent chymopapain injections. The authors reported that $83 \%$ of patients had an excellent or good outcome. ${ }^{27} \mathrm{~A}$ meta-analysis published in 2007, looking at 22 studies including over 2000 patients who underwent chemonucleolysis for herniated lumbar intervertebral discs, found it to be superior to placebo and effective in reducing pain caused by herniated lumbar discs. ${ }^{30}$

Is chemonucleolysis superior to lumbar disc surgery? A randomized control trial ( $\mathrm{RCT}$ ) was performed to determine just that, wherein 100 patients who had been experiencing sciatica with a minimum of 3 months of conservative therapy were enrolled into the study. They were randomly allocated to treatment groups of either standard lumbar discectomy or chemonucleolysis. If chemonucleolysis patients failed to show improvement at 6 months, they were offered surgery, which occurred in 10 cases of crossover. At 1 year, $93 \%$ of the chemonucleolysis group had excellent or good outcomes compared with $96 \%$ in the surgical group..$^{31}$ These results were not statistically different. At 10-13 years and 24-27-year follow-ups, some deterioration was shown in both groups but again, there was no statistical difference in outcomes between the groups. ${ }^{31}$ While manifesting a favorable response to treatment does not seem to differ between the two treatment modalities (surgery; chemonucleolysis), comparison of adverse events does differ. Infection rates, 
neurologic or hemorrhagic events, miscellaneous events, and mortality are all drastically lower in chemonucleolysis compared with surgical treatment. ${ }^{29,32}$ In addition, in studies conducted 30 years ago, chemonucleolysis cost an average of $\$ 2000$ less and required less days in the hospital post-procedure. ${ }^{28,33}$ It is also important to remember that failure to attain a successful outcome using chemonucleolysis does not necessarily affect the eligibility of a patient to undergo surgical treatment. ${ }^{27,29}$

Why is chemonucleolysis with chymopapain not in use today? Chemonucleolysis remained surrounded by considerable controversy over the past 50 years since Lyman Smith first proposed it as an option to surgery for symptomatic lumbar disc disease. Chymopapain is very allergic in that $~ 3 \%$ of the population of North America is sensitive to the papaya enzyme. This means anaphylaxis is a very serious potential complication of chymopapain. ${ }^{25,32}$ It has been shown that anaphylaxis occurs in 5 per 10,000 patients who receive the injection. ${ }^{29,34}$ Other severe adverse reactions that have been linked to chemonucleolysis include discitis, subarachnoid hemorrhage, paraplegia, and a previous association with acute transverse myelitis. ${ }^{29}$ The majority of the adverse events associated with chemonucleolysis with chymopapain can be avoided by proper patient selection and technique; however, the procedure has not been available since the early $2000 \mathrm{~s}$ secondary to safety concerns.

\section{Chemonucleolysis with collagenase}

Due to the aforementioned safety concerns associated with chymopapain, chemonucleolysis with other enzymes has been studied. Collagenase is an enzyme known to split collagen fibers. Purified collagenase is fairly specific for type II collagen fibers, which are mainly found in the NP whereas the annulus is primarily composed of type I collagen. Collagenase has also been tested in animals and found to have much lower allergic potential than does chymopapain. ${ }^{35}$ Collagenase showed an $80 \%$ success rate in 30 patients with refractory symptomatic lumbar intervertebral disc disease 8 weeks after injection when compared with placebo. ${ }^{36}$ One study of 100 patients treated with either chymopapain or collagenase showed good and excellent results in $72 \%$ and $52 \%$ of patients, respectively, at a 5 -year follow-up. ${ }^{35}$ While collagenase appears to be comparable in efficacy as chymopapain, it also has potential adverse effects. While it does not elicit the same allergic response that chymopapain does, reports of endplate erosion of adjacent vertebra, as well as hemorrhage and paraplegia, have been linked to collagenase injections. ${ }^{37}$

\section{Chemonucleolysis with chondroitinase $A B C$}

Chondroitinase $\mathrm{ABC}$ is a polysaccharidease that cleaves the side chains of proteoglycans. In beagles, it was shown to decrease disc heights as well as intradiscal pressure ${ }^{38}$ In vitro rabbit disc cells were cultured after exposure to chondroitinase and chymopapain, and it was found that cells exposed to chondroitinase were able to reestablish an extracellular matrix greater to that attributed to chymopapain. ${ }^{39}$ Animal studies showed that chondroitinase ABC is safer than both chymopapain and collagenase..$^{40}$ So far, no human studies have been published testing chondroitinase use in the intervertebral disc. On the other hand, Norcross et al demonstrated a completely opposite model in which an in vivo rat intervertebral disc injected with chondroitinase altered the biomechanics and histological parameters of the disc to a pathological degree. It induced decreased height, diminished proteoglycan content, increased stiffness, and loss of cellularity, similar to findings of degenerative disc disease. ${ }^{41}$

\section{Chemonucleolysis with matrix matalloproteinase (MMP)}

MMPs are one of the newest agents used for chemonucleolysis. MMPs are neutral secreted zinc proteases that have been shown to degrade various portions of the extracellular matrix. ${ }^{3,4}$ It appears that MMP-7 cleaves aggrecan molecules at 1000 -fold the strength of collagen type I or II. ${ }^{42}$ This means that the NP, which is comprised mainly of proteoglycans and type II collagen, would likely be the most affected portion. MMPs also act as a chemoattractant for macrophages, which also play a role in natural resorption of herniated discs. ${ }^{43}$ Both MMP-3 and MMP-7 have been shown to be present in samples of human herniated discs and have been revealed as prominent contributors to the natural resorption process of herniated discs during the desiccation process. ${ }^{44}$ Haro et al looked at the use of recombinant human MMP-7 to help facilitate the natural resorption of herniated disc tissue. When compared with chymopapain-treated human herniated disc tissue in vitro, MMP-7 treated tissue showed a similar decrease in wet weight, meaning the MMP-7 degraded the human herniated tissue comparably to what was observed using chymopapain. ${ }^{45}$ They also demonstrated that MMP-7 appeared to be as potent as chymopapain for the degradation of normal rabbit disc tissue in vivo, as well as for canine herniated disc tissue. ${ }^{45}$ While MMP-7 appeared to only degrade the structures of the nucleus, chymopapain exhibited destruction of both the nucleus and the annulus. 
This means that unlike chemonucleolysis with chymopapain, MMP-7 may facilitate resorption for all types of herniated discs (i.e., protrusion and extrusion) with negligible effects on surrounding structures. ${ }^{42,45}$ After injecting radioactive recombinant human MMP-7, it was not found in the muscle or surrounding tissues when applied correctly in canines. It appeared to have no effect on collagen fibers, neurons, axons, myelin sheaths, or astrocytes, as well as no systemic effects after both 1 and 13 weeks. ${ }^{42}$ In addition, because recombinant human MMP-7 is a human protein, there will likely be no anaphylaxis with its use clinically. ${ }^{42}$ At this point, MMP-7 appears to be a safe alternative to chymopapain although definitive studies need to be conducted to prove this in humans.

\section{Chemonucleolysis with ethanol gel}

Pure ethanol was studied as an alternative to chymopapain with positive results; however, problems arose due to its low viscosity and subsequent leakage to surrounding areas with resulting pain. ${ }^{46}$ This problem was improved upon by adding ethylcellulose, a thickening agent, to create an ethanol gel that would be easier to handle and decrease leakage to surrounding non-targeted areas. Furthermore, tungsten, a radiopaque substance, was added so that correct intradiscal placement as well as determination of any leak could be seen under fluoroscopy at the time of placement (Figure 4). ${ }^{47}$ In a recent Bellini et al study of 80 patients with cervical and lumbar disc herniations, $85 \%$ of those with lumbar herniations and $83 \%$ with cervical herniations benefited from intradiscal gelified ethanol, with reported pain reduction of at least $40 \% .{ }^{48}$ Another study of 42 patients who failed conservative treatments and underwent intradiscal ethanol gel injection found a decrease in pain intensity by $44 \%$ and $62.6 \%$ after 1 and 3 months, respectively, versus baseline $(P=0.007) .{ }^{49}$

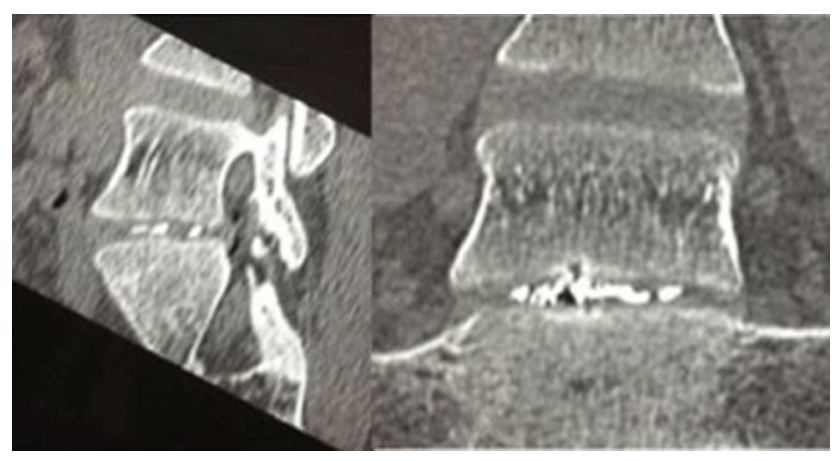

Figure 4 Fluoroscopic image demonstrating the tungsten contrast material within the intervertebral disc, indicating adequate placement of the ethanol gel injection. Note: Reproduced from Volpentesta G, De Rose M, Bosco D, et al. Lumbar percutaneous intradiscalinjection of radiopaque gelifiedethanol (Discogel) in patients with low back and radicular pain. J Pain Relief. 2014;3:145. Creative Commons Attribution License. ${ }^{47}$
In animals, it was found that gelified ethanol, when injected outside the intradiscal space, intraforaminally, epidural, and intramuscularly did not produce any morphostructural changes in the nervous or surrounding muscle tissue. ${ }^{50} \mathrm{Cur}-$ rently, studies are underway comparing outcomes of gelified ethanol injection versus surgery in patients with resistant sciatica. One is a randomized, open label, non-inferiority study of $\sim 300$ patients with completion date estimated January $2018^{51}$ (Table 1). Ethanol gel is also in a randomized, blinded, efficacy study on 40 patients in combination with pulsed radiofrequency to the intervertebral disc to see if the combination of ethanol gel with radiofrequency is superior to ethanol gel alone ${ }^{52}$ (Table 1).

\section{GFR alpha3}

Disc degeneration with eventual herniation of disc material can lead to compression and injury of peripheral nerves, leading to neuropathic pain and sciatica. Growth factors (GFs) have been used to promote sensory regrowth in the spinal cord. ${ }^{53,54}$ While GFs appear to show promise, nerve growth factor (NGF) and glial cell line-derived neurotropic factor (GDNF) produce adverse effects such as pain, bowel urgency, and paraesthesias. ${ }^{55}$ Artemin on the other hand is a neurotrophic GF that signals through the GDNF family receptor GFR alpha3 selectively, which is highly restricted to sensory neurons. ${ }^{56}$ This led researchers to believe that since artemin targets GFR alpha3 on sensory nerve fibers, it could repair peripheral nerves damaged by compression from herniated discs. In an animal model using rats, systemic administration of artemin promoted regeneration of multiple classes of nerve fibers, reestablished functional spinal connections, and restored nociceptive and sensorimotor functions. ${ }^{57}$ The treatment demonstrated restoration of function lasting at least 6 months even after a 2-day delay in treatment following nerve damage. In addition, artemin did not change the sensory thresholds of the uninjured animals. ${ }^{57}$ A single center, blinded, randomized, placebo controlled Phase I study was published in 2015 on 44 patients with unilateral sciatica after a one-time dosing of intravenous artemin. Mild improvement in pain scores was witnessed; however, pain reduction was not the primary outcome of the study. The study concluded with support for further development of artemin for treatment of neuropathic pain and stating that low amount of pain reduction was witnessed was from single dosing of artemin and that perhaps further benefit can be obtained with multiple dosing. ${ }^{58}$ A randomized, double-blind Phase II trial was completed in 2015 on 184 patients looking not only at pain reduction but also at safety and tolerability after multiple injections of intravenously administered artemin in patients with painful lumbar radiculopathy; however, no results are yet available ${ }^{59}$ (Table 1). 
Table I Furthest stage of development of the new drugs and ongoing studies

\begin{tabular}{|c|c|c|c|c|c|}
\hline Drug & Class & $\begin{array}{l}\text { Number of } \\
\text { ongoing studies }\end{array}$ & $\begin{array}{l}\text { Furthest stage of } \\
\text { development }\end{array}$ & $\begin{array}{l}\text { Total number of } \\
\text { patients enrolled in } \\
\text { all active studies }\end{array}$ & $\begin{array}{l}\text { References/clinical } \\
\text { trials }\end{array}$ \\
\hline Matrix metalloproteinases & Chemonucleolysis & 0 & Phase I & 0 & $40-43$ \\
\hline Ethanol gel & Chemonucleolysis & 2 & Phase I/II & 340 & $\begin{array}{l}\text { 44-47 } \\
\text { 48/NCT023I3350 } \\
\text { 49/NCT02343484 }\end{array}$ \\
\hline Platelet-rich plasma & Disc regeneration & 0 & Phase II & 0 & $75-76$ \\
\hline Stem cell therapy & Disc regeneration & 5 & Phase III & 564 & $\begin{array}{l}\text { 77-80, } 82 \\
81 / \text { NCT024I2735 }\end{array}$ \\
\hline Tanezumab & Nociceptor modulation & I & Phase III & 1800 & $\begin{array}{l}57-65 \\
66 / \text { NCT02528253 }\end{array}$ \\
\hline Artemin & Neuronal regrowth & 0 & Phase II & 0 & $\begin{array}{l}53-55 \\
56 / \text { NCT0I873404 }\end{array}$ \\
\hline
\end{tabular}

\section{Neuronal GFs - tanezumab}

NGF is one of the many factors that modulate nociceptive neuronal activity. It plays a role in pain signaling pathways and is released when there is tissue inflammation or nerve damage. ${ }^{60}$ Elevated levels have been shown in chronic pain conditions and it has been shown that exogenous NFG can result in hyperalgesia. ${ }^{61}$ On the other hand, a decrease in the amount of NGF leads to a reduction in the pain response. ${ }^{61,62}$ Anti-NGF has shown favorable decreases in pain behaviors in animals. ${ }^{63}$ In addition, human studies with anti-NGF have demonstrated favorable reduction in pain in chronic pain syndromes, including osteoarthritis and interstitial cystitis. ${ }^{64,65}$ Therefore, it is reasonable to assume that low back pain secondary to degenerative disc could be decreased by blocking NGF.

Tanezumab is a monoclonal antibody that has been demonstrated to have a high affinity for NGF. Katz et $\mathrm{al}^{62}$ conducted a RCT to compare reduction of low back pain in patients receiving either tanezumab infusions or oral naproxen (NSAID). Two hundred and twenty patients with chronic non-radicular pain for at least 3 months were enrolled into the study. Patients were randomly assigned to receive 1 tanezumab infusion $(200 \mu \mathrm{g} / \mathrm{kg})$, naproxen twice daily, or a placebo. Tanezumab showed a statistically significant reduction in low back pain index compared with naproxen and placebo at $4,6,8$, and 12 weeks. ${ }^{62} \mathrm{~A}$ similar study was performed on a larger scale with 1347 patients across 115 centers in USA, using standard dosages of tanezumab of 5,10, and $20 \mathrm{mg}$. This study demonstrated a statistically significant improvement in low back pain index at $4,6,8$, and 12 weeks compared with naproxen, but only in the 10 and $20 \mathrm{mg}$ dosages.$^{66}$ The $5 \mathrm{mg}$ dose of tanezumab did not show a statistical difference in improvement of pain score compared with naproxen. ${ }^{66}$ With both studies, a few adverse effects emerged. Hyperesthesias and dysesthesias during treatments were reported by
$4.6 \%$ of patients in treatment groups, with adverse events occurring more frequently at the higher dosing levels. ${ }^{66}$ In a follow-up study that addresses long-term safety and efficacy, some patients reported adverse events initially classified as osteonecrosis. This caused a temporary clinical hold placed on tanezumab in 2010; however, upon re-review of the cases, none were classified as primary osteonecrosis. ${ }^{62,66,67}$ Later, in December 2012, another clinical hold was placed just 6 months after the FDA released the previous one due to preclinical aberrant sympathetic neuronal findings. However, the final release was in March 2015 when additional preclinical studies showed that those changes on sympathetic neurons were reversible after discontinuation of tanezumab and no evidence of sympathetic nervous system function impairment was identified.

In a meta-analysis of all anti-nerve GF studies as treatment for low back pain, four RCTs were reviewed. Two of these studies were for tanezumab, which found a small-tomoderate effect on pain relief as well as small increases in functional improvement compared with placebo. ${ }^{68}$ While tanezumab did show a higher risk of developing adverse effects, it was not statistically significant and there was no higher risk for serious adverse effects. ${ }^{68}$ Currently, a 1800 patient, randomized, placebo and active control, Phase III study is underway to study the efficacy of subcutaneous tanezumab in patients with chronic low back pain. Tanezumab will be administered as a subcutaneous injection every 8 weeks over a 56-week time span with pain reduction as the primary sought outcome ${ }^{69}$ (Table 1).

\section{GFs}

Homeostasis of the tissues is maintained by a delicate balance between anabolism and catabolism of the disc cells. Traditional therapeutic strategies involving GFs attempt to upregulate anabolic factors (increase aggrecan production), 
while others attempt to downregulate catabolic factors such as pro-inflammatory cytokines or interleukin- $1 .^{70}$ The goal of GF therapy is to increase cell viability and proliferation, thereby upregulating anabolic pathways. ${ }^{7}$ By doing that, proteoglycan production will be increased. Various GFs have been shown to possess this ability upon injection into the degenerated intervertebral disc. Insulin-like growth factor 1 (IGF-1) and fibroblast growth factor (FGF) have been shown to prevent apoptosis of in vitro human disc cells. ${ }^{71}$ More viable cells may then lead to more proteoglycan production. This has been shown to be true with many GFs. Bone morphogenic protein (BMP) and transforming growth factor (TGF) beta application have been shown to increase production of collagen and aggrecan in NP cells in vitro and also promote chondrocyte-like cells, leading to increased production of aggrecan and type II collagen. ${ }^{72,73}$ Latent membrane proteins have been shown to increase intervertebral disc cell production of not only BMPs but also proteoglycans. ${ }^{74}$ Osteogenic peptide-1 has been shown to increase disc height and water content of NP in rabbits; however, it was unable to stimulate regeneration in human degenerative neuropathic pain. ${ }^{75,76} \mathrm{GF}$ therapy with the purposes of stimulating matrix synthesis has had limited success for a variety of reasons. Most degenerative discs exhibit a decrease in the already limited number of cells in the nucleus and annulus. This means matrix synthesis will be limited to the number of viable cells available. ${ }^{77}$ An additional drawback is that many of the GFs have been shown to have a short half-life, which would require multiple repeat injections. ${ }^{\text {? }}$

Platelet-rich plasma (PRP) has been studied for this purpose because it is high in GFs, including TGF, vascular endothelial GF, FGF, epidermal GF, platelet derived GF as well as others. Levi et al studied 22 patients who underwent intradiscal PRP injection with a 6-month follow-up. Categorical success rate rose from $14 \%$ at 1 month, $32 \%$ at 2 months, to $47 \%$ at 6 months of at least $50 \%$ improvement. ${ }^{78}$ A prospective, double-blinded, randomized, placebo controlled study of 47 patients showed significant improvement outcomes in the intradiscal injected PRP group with regard to pain. Function (functional rating index) $(p=0.03)$ and outcome satisfaction (North American Spine Society) ( $p=0.01)$ were revealed at 8 -week follow-up and statistically improved function at the 1-year follow-up..$^{79}$ Both of these studies conclude with a recommendation for additional trials of intradiscal PRP.

\section{Stem cell therapy}

Stem cell research with respect to healing degenerated intervertebral discs is focused on cell replacement and increase in the synthesis of proteoglycans and type II collagen. Considering that one hallmark of a degenerating disc is an absolute decrease in cell number, different cell sources have been used to attempt to encourage disc regeneration. This type of cell poses a problem because it must be able to survive long term in the harsh environment of the degenerated disc and yet still remain viable. The high osmolarity and low $\mathrm{pH}$ of disk are deleterious factors to viability, where low glucose conditions actually appear to be a favorable factor. ${ }^{80}$ Testing is currently going on with different cell sources to determine which cell lines have both feasibility in harvesting and the ability to differentiate into active disc cells.

Cell therapy has been studied in many animal models showing improvement in disc cellular degeneration. In a study carried out on 12 rabbits, the rate of degeneration was not only reduced but was also actually reversed in some cases. ${ }^{81}$ Rabbit discs were damaged through a needle puncture technique and 8 weeks after damage, allogeneic mesenchymal stem cells (MSCs), which were obtained from rabbit leg bone marrow, were transplanted into four rabbits, a hyaluronic carrier alone transferred into four rabbits and the damage was left untreated in the remaining four rabbits. MRI was conducted to obtain T2-weighted images for disc height and water content at 8 weeks before transplantation and 16 weeks after. The discs were then removed, and histological analysis was performed to evaluate the cellular architecture, collagen, and aggrecan. At 16 weeks, the MCSs with the hydrogel carriers demonstrated recovery of disc height compared with the transplanted carrier alone and the controls. Histological scoring of disc repair improved as well in the MSCs group compared with both the carrier alone and the control group. ${ }^{81}$

A pilot study was conducted in 2011 using 10 patients who failed to respond to conservative therapy for at least 6 months. Patients had stem cells harvested from their iliac crests, which were then cultured. Post-transplant, lumbar pain and disability were strongly reduced $(61.5 \%$ and $48 \%$, respectively) at 3 months, with additional modest improvement at 6 and 12 months. ${ }^{82}$ Only one patient in the study did not experience symptomatic improvement. On imaging, disc heights were not demonstrated to increase, but fluid content was shown to increase. ${ }^{82} \mathrm{~A}$ case study on two patients was conducted with human umbilical cord cells (HUC-MSCs) ${ }^{83}$ This was the first time HUC-MSCs were tested. Both the patients experienced a drastic decrease in pain on the Visual Analog Scale (7 to 1 and 8 to $2-4$ ) and disability on the Oswestry Disability Index (45 to 5-10 and 56 to $10-20$ ). ${ }^{83}$ These case studies portrayed HUC-MSC transplantation as a potentially favorable alternative for patients with degenerative 
discs because patients do not have to undergo a procedure in order to obtain the stem cells such as bone marrow aspiration or liposuction. There are several ongoing trials looking into intradiscal injections of MSCs. The largest of these being a prospective, multicenter, randomized, double-blind, and placebo-controlled Phase III trial on patients with chronic low back. This ongoing study plans to enroll 330 patients and is estimated to be completed in December $2017^{84}$ (Table 1).

Cell therapies unfortunately, due to costs of cell production, at this time remain prohibitively expensive. However, they do appear to be a reasonable alternative option for people with degenerative discs. While many surgical options have been shown to be successful, cell therapies avoid surgical side effects and can be performed on an outpatient setting because of rapid improvement in pain and functional status. ${ }^{82,85}$

\section{Limitations}

There are some limitations to this narrative review. This was not a systematic review, which means that we have not included all pertinent references. Furthermore, we have included only medications that showed some promising results in clinical trials or those being studied in human subjects in protocols that are currently ongoing, based on clinicaltrials.gov database. We could not explain in great details the respective mechanisms of action for the listed mediations due to space limitations as well as results of animal preclinical studies.

\section{Conclusion}

Disc herniation is an identifiable clinical phenomenon, usually based on symptomatology and objective imaging. While the overall prognosis of recovery from symptomatic disc herniation is relatively good, and the natural absorption of disc material typically evolves over 1 year, some patients still develop chronic pain despite conservative treatments. Chemonucleolysis has been abandoned for $>10$ years but might be revisited as a treatment option for patients with symptomatic herniated intervertebral discs. By dissolving the disc material, inflammatory mediators and mechanical pressure on small neural structures are removed. While the original enzyme, chymopapain, has been discontinued due to safety concerns, new enzymes are being studied for safety and effectiveness. Collagenase appears to have similar efficacy to chymopapain without potential adverse allergic reactions. However, it has been shown to lead to erosion of endplates on adjacent vertebra, making its use less desirable. MMP-7 is another protease shown to cleave proteoglycans and have similar efficacy as chymopapain as well as a favorable safety profile. While MMP-7 appears to be successful in vitro and in animal models, clinical trials need to be conducted to assess its safety and efficacy in humans. Initial studies show benefits of ethanol gel for both lumbar and cervical disc herniation and is further being studied given its efficacy and favorable side effect profile. Artemin is a new drug that causes stimulation of the GDRF sites, leading to regeneration of nerve and restoration of nerve function in animal models. Being that it targets receptors specific to peripheral nerves, the hope is to be able to administer the drug via systemic infusion, while maintaining only local effects. Tanezumab, a monoclonal antibody against NGF, aims to block pain signaling pathways, leading to improvement in pain and functionality in both animal models and chronic pain conditions. Initial trials comparing tanezumab to naproxen show reductions in both pain and disability, and studies are being conducted to further evaluate long-term safety and efficacy in humans. PRP has shown promising results when injected into the intervertebral disc and is currently being studied for orthopedic injuries; however, there are no active studies for low back pain registered. Use of stem cell to regenerate cells and increase disc matrix production is also currently being researched. While many cell lines have been considered, mesenchymal cells from either adipose tissue or bone marrow appear to hold the most promise. In vitro testing, animal models, and small pilot studies show success with matrix production. Several studies are currently underway, looking at long-term benefits of intradiscal injection of stem cells as well as use of different stem cell lines such as mesenchymal cells from adipose tissue or umbilical cord.

With a rising prevalence of chronic low back pain that is expected to rise with an aging population, new therapies are needed to bridge the current gap between conservative measurements and surgical interventions. It is important to remember that those discussed here, whether intravenous, subcutaneous, or via intradiscal injection, should they fail, do not preclude a patient from qualifying for surgical procedures. Spinal surgery, however, is not without potential serious morbidity risks. Post-laminectomy syndrome, also known as failed back surgery syndrome (FBSS), is a pain that continues despite surgical intervention, and is a well-described complication with notable treatment failure rates. While individual reports vary on incidence of FBSS, the report with the longest follow-up (average 14.3 years) showed $74.6 \%$ of patients had mild residual pain and $12.7 \%$ of patients had frequent mild or occasional severe pain, despite treatment intervention. This study also mentioned that $10 \%$ of patients had to undergo a revision of their surgery. ${ }^{86}$ However, if further studies are found to provide long-term benefit and improvement to quality of life, it may be able to reduce patients who undergo spinal surgery, and the inherent morbidity and mortality involved with all surgical procedures. ${ }^{87}$ We believe that with these new 
therapeutic options, we can bridge the current gap between conservative/interventional procedures and surgeries in patients with chronic back pain.

\section{Disclosure}

The authors report no conflicts of interest in this work.

\section{References}

1. From the Centers for Disease Control and Prevention. Prevalence of disabilities and associated health conditions among adults - United States. JAMA. 2001;285(12):1571-1572.

2. Simon J, McAuliffe M, Shamim F, Vuong N, Tahaei A. Discogenic low back pain. Phys Med Rehabil Clin NAm. 2014;25(2):305-317.

3. Kepler CK, Ponnappan RK, Tannoury CA, Risbud MV, Anderson DG. The molecular basis of intervertebral disc degeneration. Spine J. 2013; 13(3):318-330.

4. Raj PP. Intervertebral disc: anatomy-physiology-pathophysiologytreatment. Pain Pract. 2008;8(1):18-44.

5. Roberts S, Urban S, Jill PG. Encyclopedia of Occupational Health and Safety; 2012. Intervertebral discs. Available from: http://www. iloencyclopaedia.org/part-i-47946/musculoskeletal-system/17-6-musculoskeletal-system/intervertebral-discs. Accessed April 21, 2017.

6. Holm S, Maroudas A, Urban JP, Selstam G, Nachemson A. Nutrition of the intervertebral disc: solute transport and metabolism. Connect Tissue Res. 1981;8(2):101-119.

7. Fassett DR, Kurd MF, Vaccaro AR. Biologic solutions for degenerative disk disease. J Spinal Disord Tech. 2009;22(4):297-308.

8. Huang YC, Urban JP, Luk KD. Intervertebral disc regeneration: do nutrients lead the way? Nat Rev Rheumatol. 2014;10(9):561-566.

9. McNally DS, Shackleford IM, Goodship AE, Mulholland RC. In vivo stress measurement can predict pain on discography. Spine (Phila Pa 1976). 1996;21(22):2580-2587.

10. Johnson WE, Caterson B, Eisenstein SM, Roberts S. Human intervertebral disc aggrecan inhibits endothelial cell adhesion and cell migration in vitro. Spine (Phila Pa 1976). 2005;30(10):1139-1147.

11. Freemont AJ, Peacock TE, Goupille P, Hoyland JA, O’Brien J, Jayson MI. Nerve ingrowth into diseased intervertebral disc in chronic back pain. Lancet. 1997;350(9072):178-181.

12. Adams MA, Dolan P, Hutton WC, Porter RW. Diurnal changes in spinal mechanics and their clinical significance. J Bone Joint Surg Br. 1990; 72(2):266-270.

13. Wade KR, Robertson PA, Thambyah A, Broom ND. How healthy discs herniate: a biomechanical and microstructural study investigating the combined effects of compression rate and flexion. Spine (Phila Pa 1976). 2014;39(13):1018-1028.

14. Guterl CC, See EY, Blanquer SB, et al. Challenges and strategies in the repair of ruptured annulus fibrosus. Eur Cell Mater. 2013;25:1-21.

15. Deyo RA, Weinstein JN. Low back pain. $N$ Engl J Med. 2001;344(5): 363-370

16. Porchet F, Wietlisbach V, Burnand B, Daeppen K, Villemure JG, Vader JP. Relationship between severity of lumbar disc disease and disability scores in sciatica patients. Neurosurgery. 2002;50:1253-1259; discussion 1259-1260.

17. Saal JA. Natural history and nonoperative treatment of lumbar disc herniation. Spine (Phila Pa 1976). 1996;21(24 Suppl):2S-9S.

18. Boden SD, Davis DO, Dina TS, Patronas NJ, Wiesel SW. Abnormal magnetic-resonance scans of the lumbar spine in asymptomatic subjects. A prospective investigation. J Bone Joint Surg Am. 1990;72(3):403-408.

19. Bozzao A, Gallucci M, Masciocchi C, Aprile I, Barile A, Passariello R. Lumbar disk herniation: MR imaging assessment of natural history in patients treated without surgery. Radiology. 1992;185(1):135-141.

20. Mehling WE, Gopisetty V, Bartmess E, et al. The prognosis of acute low back pain in primary care in the United States: a 2-year prospective cohort study. Spine (Phila Pa 1976). 2012;37(8):678-684.

21. Jordan J, Konstantinou K, O’Dowd J. Herniated lumbar disc. BMJ Clin Evid. 2011;2011.
22. Riew KD, Yin Y, Gilula L, et al. The effect of nerve-root injections on the need for operative treatment of lumbar radicular pain. A prospective, randomized, controlled, double-blind study. J Bone Joint Surg Am. 2000;82-A(11):1589-1593.

23. Zhai J, Zhang L, Li M, et al. Epidural injection with or without steroid in managing chronic low-back and lower extremity pain: a meta-analysis of 10 randomized controlled trials. Am J Ther. Epub 2015 May 29.

24. Smith L. Enzyme dissolution of the nucleus pulposus in humans. JAMA. 1964;187:137-140.

25. Smith L. Chemonucleolysis. Personal history, trials, and tribulations. Clin Orthop Relat Res. 1993;287:117-124.

26. Kim YS, Chin DK, Yoon DH, Jin BH, Cho YE. Predictors of successful outcome for lumbar chemonucleolysis: analysis of 3000 cases during the past 14 years. Neurosurgery. 2002;51(5 Suppl):S123-S128.

27. Guha AR, Debnath UK, D'Souza S. Chemonucleolysis revisited: a prospective outcome study in symptomatic lumbar disc prolapse. J Spinal Disord Tech. 2006;19(3):167-170.

28. Hill GM, Ellis EA. Chemonucleolysis as an alternative to laminectomy for the herniated lumbar disc. Experience with patients in a private orthopedic practice. Clin Orthop Relat Res. 1987;225:229-233.

29. Nordby EJ, Wright PH. Efficacy of chymopapain in chemonucleolysis. A review. Spine (Phila Pa 1976). 1994;19(22):2578-2583.

30. Couto JM, Castilho EA, Menezes PR. Chemonucleolysis in lumbar disc herniation: a meta-analysis. Clinics (Sao Paulo). 2007;62(2):175-180.

31. Wardlaw D, Rithchie IK, Sabboubeh AF, Vavdha M, Downing M, Eastmond CJ. Prospective randomized trial of chemonucleolysis compared with surgery for soft disc herniation with 1-year, intermediate, and long-term outcome: part II: the radiological outcome. Spine (Phila Pa 1976). 2013;38(17):E1058-E1064.

32. Nordby EJ, Wright PH, Schofield SR. Safety of chemonucleolysis. Adverse effects reported in the United States, 1982-1991. Clin Orthop Relat Res. 1993;293:122-134.

33. Javid MJ, Nordby EJ, Ford LT, et al. Safety and efficacy of chymopapain (Chymodiactin) in herniated nucleus pulposus with sciatica. Results of a randomized, double-blind study. JAMA. 1983;249(18):2489-2494.

34. Brown MD. Update on chemonucleolysis. Spine (Phila Pa 1976). 1996;21(24 Suppl):62S-68S.

35. Wittenberg RH, Oppel S, Rubenthaler FA, Steffen R. Five-year results from chemonucleolysis with chymopapain or collagenase: a prospective randomized study. Spine (Phila Pa 1976). 2001;26(17):1835-1841.

36. Bromley JW, Varma AO, Santoro AJ, Cohen P, Jacobs R, Berger L. Double-blind evaluation of collagenase injections for herniated lumbar discs. Spine (Phila Pa 1976). 1984;9(5):486-488.

37. Brown MD, Tompkins JS. Chemonucleolysis (discolysis) with collagenase. Spine (Phila Pa 1976). 1986;11(2):123-130.

38. Yamada K, Tanabe S, Ueno H, et al. Investigation of the short-term effect of chemonucleolysis with chondroitinase ABC. J Vet Med Sci. 2001; 63(5):521-525.

39. Chiba K, Masuda K, Andersson GB, Momohara S, Thonar EJ. Matrix replenishment by intervertebral disc cells after chemonucleolysis in vitro with chondroitinase $\mathrm{ABC}$ and chymopapain. Spine J. 2007; 7(6):694-700.

40. Sugimura T, Kato F, Mimatsu K, Takenaka O, Iwata H. Experimental chemonucleolysis with chondroitinase $\mathrm{ABC}$ in monkeys. Spine (Phila Pa 1976). 1996;21(2):161-165.

41. Norcross JP, Lester GE, Weinhold P, Dahners LE. An in vivo model of degenerative disc disease. J Orthop Res. 2003;21(1):183-188.

42. Haro H, Nishiga M, Ishii D, et al. Experimental chemonucleolysis with recombinant human matrix metalloproteinase 7 in human herniated discs and dogs. Spine J. 2014;14(7):1280-1290.

43. Doita M, Kanatani T, Ozaki T, Matsui N, Kurosaka M, Yoshiya S. Influence of macrophage infiltration of herniated disc tissue on the production of matrix metalloproteinases leading to disc resorption. Spine (Phila Pa 1976). 2001;26(14):1522-1527.

44. Haro H, Crawford HC, Fingleton B, Shinomiya K, Spengler DM, Matrisian LM. Matrix metalloproteinase-7-dependent release of tumor necrosis factor-alpha in a model of herniated disc resorption. $J$ Clin Invest. 2000;105(2):143-150. 
45. Haro H, Komori H, Kato T, et al. Experimental studies on the effects of recombinant human matrix metalloproteinases on herniated disc tissues-how to facilitate the natural resorption process of herniated discs. J Orthop Res. 2005;23:412-419.

46. Riquelme C, Musacchio M, Mont'Alverne F, Tournade A. Chemonucleolysis of lumbar disc herniation with ethanol. J Neuroradiol. 2001; 28(4):219-229.

47. Volpentesta G, De Rose M, Bosco D, et al. Lumbar percutaneous intradiscal injection of radiopaque gelified ethanol (Discogel) in patients with low back and radicular pain. J Pain Relief. 2014;3:145.

48. Bellini M, Romano DG, Leonini S, et al. Percutaneous injection of radiopaque gelified ethanol for the treatment of lumbar and cervical intervertebral disk herniations: experience and clinical outcome in 80 patients. AJNR Am J Neuroradiol. 2015;36(3):600-605.

49. Touraine S, Damiano J, Tran O, Laredo JD. Cohort study of lumbar percutaneous chemonucleolysis using ethanol gel in sciatica refractory to conservative treatment. Eur Radiol. 25(11):3390-3397.

50. Guarnieri G, De Dominicis G, Muto M. Intradiscal and intramuscular injection of discogel $(\circledR)$ - radiopaque gelified ethanol: pathological evaluation. Neuroradiol J. 2010;23(2):249-252.

51. Clinicaltrials.gov. Intradisca discogel in resistant sciatica. Available from: https://clinicaltrials.gov/ct2/show/NCT02313350. NLM identifier: NCT02313350 Accessed June 10, 2016.

52. Clinicaltrials.gov. Intradiscal gelified ethanol and pulsed radiofrequency versus gelified ethanol Injection for discogenic low back pain. Available from: https://clinicaltrials.gov/ct2/show/NCT02343484. NLM identifier: NCT02343484 Accessed March 25, 2016.

53. Ramer MS, Priestley JV, McMahon SB. Functional regeneration of sensory axons into the adult spinal cord. Nature. 2000;403(6767): 312-316.

54. Ramer MS, Bradbury EJ, McMahon SB. Nerve growth factor induces P2X(3) expression in sensory neurons. J Neurochem. 2001;77(3): 864-875.

55. Thoenen H, Sendtner M. Neurotrophins: from enthusiastic expectations through sobering experiences to rational therapeutic approaches. Nat Neurosci. 2002;(5 Suppl):1046-1050.

56. Honma Y, Araki T, Gianino S, et al. Artemin is a vascular-derived neurotropic factor for developing sympathetic neurons. Neuron. 2002;35(2): 267-282.

57. Wang R, King T, Ossipov MH, et al. Persistent restoration of sensory function by immediate or delayed systemic artemin after dorsal root injury. Nat Neurosci. 2008;11(4):488-496.

58. Rolan PE, O’Neill G, Versage E, et al. First-in-human, double-blind, placebo-controlled, randomized, dose-escalation study of BG00010, a glial cell line-derived neurotrophic factor family member, in subjects with unilateral sciatica 2015. PLoS One. 2015;10(5):e0125034.

59. Clinicaltrials.gov. BG00010 (Neublastin) phase 2 multiple dose adaptive design in participants with painful lumbar radiculopathy (SPRINT). Available from: https://clinicaltrials.gov/ct2/show/study/NCT01873404. NLM identifier: NCT01873404 Accessed March 25, 2016.

60. Mantyh PW, Koltzenburg M, Mendell LM, Tive L, Shelton DL. Antagonism of nerve growth factor-TrkA signaling and the relief of pain. Anesthesiology. 2011;115(1):189-204.

61. Watson JJ, Allen SJ, Dawbarn D. Targeting nerve growth factor in pain: what is the therapeutic potential? Bio Drugs. 2008;22(6):349-359.

62. Katz N, Borenstein DG, Birbara C, et al. Efficacy and safety of tanezumab in the treatment of chronic low back pain. Pain. 2001;152(10): $2248-2258$.

63. Koewler NJ, Freeman KT, Buus RJ, et al. Effects of a monoclonal antibody raised against nerve growth factor on skeletal pain and bone healing after fracture of the C57BL/6J mouse femur. J Bone Miner Res. 2007;22(11):1732-1742.

64. Brown MT, Murphy FT, Radin DM, Davignon I, Smith MD, West CR. Tanezumab reduces osteoarthritic knee pain: results of a randomized, double-blind, placebo-controlled phase III trial. J Pain. 2012;13(8):790-798.

65. Evans RJ, Moldwin RM, Cossons N, Darekar A, Mills IW, Scholfield D. Proof of concept trial of tanezumab for the treatment of symptoms associated with interstitial cystitis. J Urol. 2011;185(5):1716-1721.
66. Kivitz AJ, Gimbel JS, Bramson C, et al. Efficacy and safety of tanezumab versus naproxen in the treatment of chronic low back pain. Pain. 2013;154(7):1009-1021.

67. Gimbel JS, Kivitz AJ, Bramson C, et al. Long-term safety and effectiveness of tanezumab as treatment for chronic low back pain. Pain. 2014; 155(9):1793-1801.

68. Leite VF, Buehler AM, El Abd O, et al. Anti-nerve growth factor in the treatment of low back pain and radiculopathy: a systematic review and a meta-analysis. Pain Physician. 2014;17(1):E45-E60.

69. Clinicaltrials.gov. A phase 3 study of tanezumab for chronic low back pain (TANGO). Available from: https://Clinicaltrials.gov/ct2/show/ NCT02528253. NLM identifier: NCT02528253 Accessed March 25, 2016.

70. Masuda K. Biological repair of the degenerated intervertebral disc by the injection of growth factors. Eur Spine J. 2008;17(Suppl 4):441-451.

71. Gruber HE, Norton HJ, Hanley EN Jr. Anti-apoptotic effects of IGF-1 and PDGF on human intervertebral disc cells in vitro. Spine (Phila Pa 1976). 2000;25(17):2153-2157.

72. Thompson JP, Oegema TR Jr, Bradford DS. Stimulation of mature canine intervertebral disc by growth factors. Spine (Phila Pa 1976). 1991;16(3):253-260.

73. Walsh AJ, Bradford DS, Lotz JC. In vivo growth factor treatment of degenerated intervertebral discs. Spine (Phila Pa 1976). 2004;29(2):156-163.

74. Yoon ST, Park JS, Kim KS, et al. ISSLS prize winner: LMP-1 upregulates intervertebral disc cell production of proteoglycans and BMPs in vitro and in vivo. Spine (Phila Pa 1976). 2004;29(23):2603-2611.

75. Masuda K, Imai Y, Okuma M, et al. Osteogenic protein-1 injection into a degenerated disc induces the restoration of disc height and structural changes in the rabbit annular puncture model. Spine (Phila Pa 1976). 2006;31(7):742-754.

76. van Dijk BG, Potier E, van Dijk M, Creemers LB, Ito K. Osteogenic protein 1 does not stimulate a regenerative effect in cultured human degenerated nucleus pulposus tissue. J Tissue Eng Regen Med. Epub 2015 Nov 27.

77. Masuda K, Oegema TR Jr, An HS. Growth factors and treatment of intervertebral disc degeneration. Spine (Phila Pa 1976). 2004;29(23): 2757-2769.

78. Levi D, Horn S, Tyszko S, Levin J, Hecht-Leavitt C, Walko E. Intradiscal platelet-rich plasma injection for chronic discogenic low back pain: preliminary results from a prospective trial. Pain Med. 2016;17(6):1010-1022.

79. Tuakli-Wosornu YA, Terry A, Boachie-Adjei K, et al. Lumbar intradiskal platelet-rich plasma (PRP) injections: a prospective, double-blind, randomized controlled study. $P M R$. 2016;8(1):1-10.

80. Sivakamasundari V, Lufkin T. Stemming the degeneration: IVD stem cells and stem cell regenerative therapy for degenerative disc disease. Adv Stem Cells. 2013;2013.

81. Subhan RA, Puvanan K, Murali MR, et al. Fluoroscopy assisted minimally invasive transplantation of allogenic mesenchymal stromal cells embedded in HyStem reduces the progression of nucleus pulposus degeneration in the damaged intervertebral [corrected] disc: a preliminary study in rabbits. Scientific World J. 2014;2014:818502.

82. Orozco L, Soler R, Morera C, Alberca M, Sanchez A, Garcia-Sancho J. Intervertebral disc repair by autologous mesenchymal bone marrow cells: a pilot study. Transplantation. 2011;92(7):822-828.

83. Pang X, Yang H, Peng B. Human umbilical cord mesenchymal stem cell transplantation for the treatment of chronic discogenic low back pain. Pain Physician.2014;17(4):E525-E530.

84. Clinicaltrials.gov. Safety and efficacy of rexlemestrocel-L in subjects with chronic discogenic lumbar back pain. Available from: https:// clinicaltrials.gov/ct2/show/record/NCT02412735. NLM identifier: NCT02412735 Accessed March 26, 2016.

85. Gou S, Oxentenko SC, Eldrige JS, et al. Stem cell therapy for intervertebral disk regeneration. Am J Phys Med Rehabil. 2014;93(11 Suppl 3): S122-S131.

86. Yorimitsu E, Chiba K, Toyama Y, Hirabayashi K. Long-term outcomes of standard discectomy for lumbar disc herniation: a follow-up study of more than 10 years. Spine (Phila Pa 1976). 2001;26(6):652-657.

87. Skaf G, Bouclaous C, Alaraj A, Chamoun R. Clinical outcome of surgical treatment of failed back surgery syndrome. Surg Neurol. 2005; 64:483-488, discussion 488-489. 
The Journal of Pain Research is an international, peer reviewed, open access, online journal that welcomes laboratory and clinical findings in the fields of pain research and the prevention and management of pain. Original research, reviews, symposium reports, hypothesis formation and commentaries are all considered for publication
The manuscript management system is completely online and includes a very quick and fair peer-review system, which is all easy to use. Visit http://www.dovepress.com/testimonials.php to read real quotes from published authors.

Submit your manuscript here: https://www.dovepress.com/journal-of-pain-research-journal 